\title{
ALLIUM URSINUM L. LEAVES COMPONENTS MODIFIED THE PHYSICO-CHEMICAL PROPERTIES OF RED BLOOD CELLS PROTECTING THEM FROM THE EFFECTS OF OXIDATIVE STRESS
}

\author{
SYLWIA CYBORAN-MIKOŁAJCZYK ${ }^{1 *}$, HALINA KLESZCZYŃSKA', \\ JAN OSZMIAŃSKI ${ }^{2}$ and ROBERT PASŁAWSKI ${ }^{3}$
}

${ }^{1}$ Department of Physics and Biophysics, Wrocław University of Environmental and Life Sciences, Norwida 25, 50-375 Wrocław, Poland

${ }^{2}$ Department of Fruit, Vegetable and Plant Nutraceutical Technology,

Wrocław University of Environmental and Life Sciences,

J. Chełmońskiego 37/41, 51-630 Wrocław, Poland

${ }^{3}$ Veterinary Center Nicoalus Copernicus University Toruń, ul. Wileńska 4, 87-100 Toruń, Poland

\begin{abstract}
The aim of the study is to determine the antioxidant activity and influence of Allium ursinum L. leaf extract on physicochemical and electrical properties of erythrocytes in order to help clarify its capacity to alleviate oxidative stress. The phenolic compounds were isolated from the leaves of bear garlic. The composition of the extract is well documented and was earlier analyzed quantitatively and qualitatively by UPLC methods. The impact of the extract constituents on the erythrocyte membrane properties was determined on the basis of its osmotic fragility, fluidity, organization of the hydrophilic area and transmembrane potential with spectrophotometric and fluorimetric methods. Furthermore, the effect of the extract on the level of membrane lipid oxidation and also on the extent of hemolysis of erythrocytes subjected to oxidation induced by AAPH compound was determined. The study showed that the extract at $40 \mu \mathrm{g} / \mathrm{mL}$ lowers the level of erythrocyte hemolysis caused by $76.8 \%$ oxidation. In addition, the extract protects lipid membranes against hemolysis better than ascorbic acid. The extract, in examined range of concentrations, did not induce hemolysis of erythrocytes, caused a small decrease in their electric potential and osmotic fragility, and increased disorder of the polar heads of membrane lipids. The high antioxidant efficiency and determined effects of the interaction of bear garlic leaf extract with the erythrocyte membrane suggest that its constituents may not only protect cells against free radicals but also mitigate the effects of oxidative stress.
\end{abstract}

Keywords: transmembrane potential, bear garlic extract, fluidity, AAPH oxidation, biological membrane, erythrocytes

Nowadays, people are more vulnerable to a range of serious diseases - a fact connected with civilizational development - such as cancer, arthritis, diabetes, hypertension, coronary, Alzheimer and Parkinson diseases. These are practically incurable, and hence the difficult situation of the sufferers. One can only diminish suffering and bring relief by applying adequate medicines and therapy. In view of that, in recent years intensive studies have been conducted to find effective compounds of plant origin that would protect the human organism from the onset of various diseases as well as assist therapy, without side effects. Substances derived from plants have been in use for centuries, owing to observed health-supporting effects. Presently, thanks to extensive scientific research, the composition of various plant extracts are known in detail, as well as their properties and effects on organisms at the cell and molecular level $(1,2)$. A large group of plant compounds has not yet been subjected to the basic biophysical investigation that could lead to clarifying the molecular mechanism of their healing effect on the organism. Garlic is one of the significant plants that have been taken by man for centuries, for seasoning and mostly as a natural, harmless antibiotic of documented healing effects. Numerous varieties of garlic contain substances that exhibit a broad spectrum of protective and healing effects on the organism $(3,4)$.

\footnotetext{
* Corresponding author: e-mail: sylwia.cyboran@upwr.edu.pl
} 
Among medicinal and seasoning plants a great discovery of recent years is the bear garlic (Allium ursinum L.), though it has been in use for centuries. As documented by scientific research, it has a markedly broader health-supporting activity than the common garlic (Allium sativum), mainly due to its richer content of organic sulfur compounds (5). Bear garlic grows wild in the forests of Europe and Asia, and its long lancet leaves are the main edible part of the plant, containing most of its healthy compounds. According to legend, its name derives from its original application as a plant eaten to help bears gain new strength after awakening from winter sleep. Such observations inspired herbalists to use the leaves of bear garlic for treating human ailments. Owing to the content of sulfur compounds, bear garlic exhibits antiviral, antifungal and antiparasite activity, and that is why it is seen as an effective natural antibiotic, which protects especially the respiratory and digestive system (6). It also supports the digestive system due to bile production and cholagogic properties and protects the organism against diseases by stimulating the production of antibodies necessary in resisting infections. It has detoxing effects on organisms owing to organic compounds of sulfur that bind toxins into chemical structures easily removable from the organism or converts them into nontoxic compounds (7). Bear garlic is a natural source of sulfur for an organism, the element that influences on keratin, the protein affecting skin complexion, hair and nails. The sulfur organic compounds in bear garlic, whose amounts are several times greater than in common garlic, make it an effective anticancer agent, brain cancer including (8). In addition, it is an effective medicine in rheumatic diseases, facilitates regeneration and proper functioning of joints, thanks to its sulfur which is the main constituent of connecting tissue and collagen. Bear garlic protects the cardiovascular system, increasing the level of HDL cholesterol and lowering that of LDL cholesterol and triglycerides, which results in a lower risk of heart and brain stroke or cardiovascular disease (9). The content of iron and a large content of adenosine in bear garlic are responsible for its positive impact on the circulatory system, lowers blood viscosity and pressure, broadening blood vessels and thus lowering the risk of clogging. Leaves of that plant are markedly richer in polyphenols than stems, bulbs and flowers (8). It has been shown that kaempferol glycosides, the main polyphenols of bear garlic $(10,11)$ lower blood sugar level, and also exhibit antiphobic, analgesic and analergic activity $(12,13)$. Such a high content of polyphenolic substances in the leaves of bear garlic is evidently the reason why garlic extract has a high antioxidative capacity $(14,15)$. The high concentration of biologically active polyphenols in the leaves and their ability to scavenge free radicals prompted us to undertake studies on the biological activity of bear garlic extract in relation to erythrocytes and their membranes.

At present, a small number of papers is focused on biophysical investigations that aim at explaining the molecular effects of the interaction between substances contained in bear garlic and the biological membrane. It has been shown that the compounds, e.g. the volatile oils and allicin, cause the lipid bilayer fluidity to diminish $(16,17)$. However, there are no publications which would specify the effect of the polyphenolic fraction of bear garlic on the physical properties of cells and membranes. Knowing the results of that interaction will allow us to determine its molecular mechanism, enrich the present knowledge and rationally utilize the garlic polyphenols, in the form of extracts or functional food components, for health protection and treatment of many serious diseases. The purpose of the study is to determine the antihemolytic and antioxidant activity of bear garlic extract in relation to cells and biological membranes and to specify its influence on their physical properties. In this study, the erythrocyte and its membrane served as an example and model of the living cell and its membrane.

\section{MATERIALS AND REAGENTS}

\section{Erythrocytes and erythrocyte membranes}

The studies were conducted on pig erythrocytes and isolated erythrocyte membranes (ghosts). The choice of pig erythrocytes was dictated by the fact that this cell's percentage share of lipids is closest to that of the human erythrocyte, and the blood was easily available. The erythrocytes were obtained from fresh, heparinized pig blood. Erythrocyte membranes were obtained from fresh blood using the Dodge method (18) whereas their content in the samples was determined on the basis of protein concentration, which was assayed using a modified Lowry method (19), and it was $10 \mathrm{mg} / \mathrm{mL}$.

The fluorescent probes - 6-dodecanoyl-2-dimethylaminonaphthalene (Laurdan), 1,6-diphenyl1,3,5-hexatriene (DPH) and 3,3'-dippropylthiadicarbocyanine iodide $\left(\mathrm{DiSC}_{3}(5)\right)$ were purchased from Molecular Probes, Eugene, Oregon, USA. Oxidation inducer 2,2'-azobis(2-amidinopropane) dihydrochloride (AAPH), ionophore valinomycin and antioxidant standard L(+) ascorbic acid (AA) were purchased from Sigma-Aldrich, Inc., Steinheim, Germany. All other reagents were analytically pure. 
Extract preparation and its phenolic composition

The extract from Allium ursinum L. yellow leaves was obtained from the Department of Fruit, Vegetable and Plant Nutraceutical Technology and was prepared according to the procedure described in (10). Phenolic compounds in the extract were identified with the UPLC-PDA-Q/TOF-MS method. The detailed qualitative and quantitative analysis of polyphenols contained in the extract was published earlier in (10).

\section{METHODS}

Hemolytic activity of the extract. Protection of erythrocytes against oxidative hemolysis induced by АAPH

The hemolytic experiments were conducted on fresh, heparinized pig blood. For washing the erythrocytes, and in the experiments performed, an isotonic phosphate solution of $\mathrm{pH} 7.4$ was used. Upon removing plasma the erythrocytes were washed four times in the phosphate solution and then incubated in the same solution but containing appropriate amounts of the compound studied. The modification was conducted at $37^{\circ} \mathrm{C}$ for $1 \mathrm{~h}$, each sample containing $10 \mathrm{~mL}$ of erythrocyte suspension of $1.2 \%$ hematocrit, stirred continuously. After modification $1 \mathrm{~mL}$ samples were taken, centrifuged and the supernatant assayed for hemoglobin content using a spectrophotometer (Specord 40, Analityk Jena) at 540 $\mathrm{nm}$ wavelength. Hemoglobin concentration in the supernatant, expressed as a percentage of hemoglobin concentration in the supernatant of totally hemolyzed cells, was assumed as the measure of the extent of hemolysis.

To test the effect of the extract on hemolysis induced by free radicals, red blood cells (RBCs) were pre-incubated with varying concentrations of extracts at $37^{\circ} \mathrm{C}$ for $1 \mathrm{~h}$. Hemolysis of RBCs was carried out by mixing a $1.2 \%$ suspension of RBCs (unmodified or modified by extract) in phosphate buffer of $\mathrm{pH} 7.4$ with AAPH solution (final concentration $40 \mathrm{mmol} / \mathrm{L}$ ). This reaction mixture was incubated for $3 \mathrm{~h}$ at $37^{\circ} \mathrm{C}$. After incubation, samples were centrifuged for $15 \mathrm{~min}(2000 \mathrm{~g})$ at $23^{\circ} \mathrm{C}$. The extent of hemolysis was determined spectrophotometrically by measuring the absorbance of the supernatant at $\lambda=540 \mathrm{~nm}$. For reference, RBCs were treated with redistilled water and the absorbance of the hemolysate was used as $100 \%$ hemolysis. The $\mathrm{IC}_{50}$ concentrations of extracts, responsible for $50 \%$ inhibition of hemolysis induced by AAPH, were determined and compared with $\mathrm{IC}_{50}$ values determined for the standard antioxidant L (+) ascorbic acid.
Protection of erythrocyte membrane from oxidation induced by AAPH

The antioxidant activity of extract towards biological membranes was determined by fluorimetric methods using AAPH as oxidation inducer. TMADPH probe was used in the experiments. Erythrocyte membranes (ghosts) with and without (control) addition of extract, were suspended in a phosphate buffer of $\mathrm{pH} 7.4$ and treated with the chemical oxidation inducer AAPH for $30 \mathrm{~min}$. Free radicals, released in the process of hemolytic decomposition of AAPH, cause quenching of TMA-DPH fluorescence, decreasing the probe's fluorescence. As a measure of the extent of lipid oxidation the relative fluorescence was used, i.e. the ratio of fluorescence of AAPH-oxidized probe to the initial fluorescence of the probe. Here, the relative fluorescence of an erythrocyte ghost suspension that contained the dye oxidized with AAPH was used as a control, while the blank was the relative fluorescence of a suspension of the same concentration but not oxidized. A Cary Eclipse (Varian) spectrofluorimeter was used to measure free radical concentrations in the samples. Excitation and emission wavelengths were $\lambda_{\text {ex }}$ $=364 \mathrm{~nm}$ and $\lambda_{\text {em }}=430 \mathrm{~nm}$. The measure of lipid oxidation was the relative change of fluorescence intensity, $F / F_{0}$, where $F_{0}$ is the initial fluorescence and $\mathrm{F}$ the one measured during the oxidation procedure (20). The percentage of lipid oxidation inhibition was calculated from the formula:

$$
\% \text { of oxidation inhibition }=\frac{\left(I F_{x}-I F_{u}\right)}{\left(I F_{k}-I F_{u}\right)}
$$

where: $\mathrm{IF}_{x}=$ relative fluorescence of oxidized by AAPH sample, for $30 \mathrm{~min}$ in the presence of the extract; $\mathrm{IF}_{u}=$ relative fluorescence of the control sample, oxidized by AAPH, without the extract, measured after 30 min.; $\mathrm{IF}_{k}=$ relative fluorescence of the blank sample, not subjected to oxidation procedure, measured after $30 \mathrm{~min}$.

The effect of extract on erythrocyte membrane fluidity and its hydrophilic area organization

The effect of polyphenols on fluidity and mobility/hydration of the polar heads of lipids in the erythrocyte membrane (ghosts) was investigated using the fluorimetric method. The fluorescent probes Laurdan and DPH were used because each of them is incorporated into different regions of the lipid bilayer. The active part (fluorophore) of DPH probe is located in the hydrophobic and that of Laurdan in the hydrophilic region of the bilayer, respectively. Such differentiated incorporation of the probes gives an insight into the structural changes caused by incorporation of extract (21). The 
erythrocyte membranes were suspended in isotonic phosphate solution of $\mathrm{pH} 7.4$, at a quantity such that the protein concentration in the samples amounted to approx. $100 \mu \mathrm{g} / \mathrm{mL}$. The control samples contained erythrocyte ghosts and a fluorescent probe, while the investigated samples contained in addition appropriate concentrations of the compound studied. The concentration of the probes in the samples was $10 \mathrm{mM}$, while concentrations of the extract were within the range $0.005-0.05 \mathrm{mg} / \mathrm{mL}$. The measurements were conducted at $37^{\circ} \mathrm{C}$ with a fluorimeter (CARRY Eclipse of VARIAN) equipped with a Peltier temperature controller DBS (temp. accuracy $\pm 0.1^{\circ} \mathrm{C}$ ). The excitation and emission wavelengths for DPH probe were $\lambda_{\mathrm{ex}}=360 \mathrm{~nm}, 1_{\mathrm{em}}=425 \mathrm{~nm}$. The excitation wavelength for Laurdan was $360 \mathrm{~nm}$, and the emitted fluorescence was recorded at two wavelengths, 440 and $490 \mathrm{~nm}$.

The GP was calculated with the formula (22):

$$
G P=\frac{I_{b}-I_{r}}{I_{b}+I_{r}}
$$

where: $I_{b}$ is fluorescence intensity at $=440 \mathrm{~nm}$ and $I_{r}$ is fluorescence intensity at $=490 \mathrm{~nm}$.

The obtained values of GP were compared with those of unmodified erythrocytes. The rise in GP value was interpreted in terms of bilayer dehydration and/or increase in lipid packing density and vice versa.

Fluorescence anisotropy (A) for DPH probe was calculated using the formula (21):

$$
A=\frac{\left(I_{I I}-G I_{I}\right)}{\left(I_{I I}+2 G I_{I}\right)}
$$

Where: $I_{I I}$ and $I_{I}$ are fluorescence intensities observed in directions parallel and perpendicular, respectively, to the polarization direction of the exciting wave. $\mathrm{G}$ is an apparatus constant dependent on the emission wavelength. Increase in DPH anisotropy indicates a decrease in membrane fluidity and vice versa.

\section{The effect of extract on osmotic resistance of ery- throcytes}

Osmotic resistance assay was performed on fresh pig blood. Full blood was centrifuged for 3 $\mathrm{min}, 2500 \mathrm{rev} / \mathrm{min}$, at $4^{\circ} \mathrm{C}$ to remove the plasma and leucocytes. The erythrocytes obtained were washed thrice with a cool (ca. $\left.4^{\circ} \mathrm{C}\right) 310 \mathrm{mOsm}$ PBS (phosphate buffered saline, $\mathrm{pH}$ 7.4) isotonic solution. Next, a $2 \%$ red cell suspension containing extract of $0.01 \mathrm{mg} / \mathrm{mL}$ concentration was prepared and left for $1 \mathrm{~h}$ at $37^{\circ} \mathrm{C}$ with continuous stirring. After this modification, the suspension of erythrocytes was centrifuged for $15 \mathrm{~min}$ at room temperature in order to remove the cells from the extract solution. From the cell sediment $100 \mu \mathrm{L}$ samples of the extract-modified cells were taken and suspended in test tubes containing $\mathrm{NaCl}$ solutions of $0.5-0.86 \%$ concentration and in an isotonic $(0.9 \%) \mathrm{NaCl}$ solution. In solutions of the same concentrations were also suspended unmodified red blood cells that constituted the control for osmotic resistance determinations. Then, the suspension was stirred and centrifuged under the above-stated conditions. After that, the percentage of hemolysis was measured with a spectrophotometer at $\lambda=540 \mathrm{~nm}$. On the basis of the results, the relation was determined between the percentage of hemolysis and $\mathrm{NaCl}$ concentration in the solution. Next, using obtained plots, the $\mathrm{NaCl}$ concentrations $\left(\mathrm{C}_{50}\right)$ that caused $50 \%$ hemolysis were found. The $\mathrm{C}_{50}$ values were taken as a measure of osmotic resistance. If a determined sodium chloride concentration is higher than that of control cells, the osmotic resistance of the erythrocytes is regarded to be lower, and vice versa.

\section{The effect of extract on erythrocyte transmem- brane potential}

The transmembrane potential of erythrocytes was measured with the fluorescence indicator $\mathrm{DiSC}_{3}(5)$ according to a procedure described in (23), with minor modification. Briefly, $1 \mathrm{~mL}$ of erythrocytes solution of $1.2 \%$ hematocrit was incubated with increasing concentrations of extract for $1 \mathrm{~h}$ at $37^{\circ} \mathrm{C}$. After this modification, $2 \mathrm{~mL}$ of $310 \mathrm{mOsm}$ PBS was added to the suspension, centrifuged for 15 min at room temperature and the supernatant removed, in order to separate the cells from the extract solution. Next, $220 \mu \mathrm{L}$ samples were suspended in buffered saline, containing $10 \mathrm{mmol} / \mathrm{L}$ Tris- $\mathrm{HCl}$, pH 7.4 and $150 \mathrm{mmol} / \mathrm{L}(\mathrm{KCl}+\mathrm{NaCl})$, with $\mathrm{K}^{+}$concentration increased from 50 to 140 $\mathrm{mmol} / \mathrm{L}$. Next, an ethanolic solution of $\mathrm{DiSC}_{3}(5)$ was added to a final concentration of $2 \mathrm{mmol} / \mathrm{L}$, and samples were incubated for $10 \mathrm{~min}$ at room temperature. The fluorescence intensity of the dye (I) was measured with a fluorimeter (CARRY Eclipse of VARIAN) at $660 \mathrm{~nm}$ and excited at 625 $\mathrm{nm}$. Then, the ionophore valinomycin was added to the samples to a final concentration of $1 \mathrm{mmol} / \mathrm{L}$, incubated for $10 \mathrm{~min}$ and fluorescence intensity of the probe $\left(\mathrm{I}_{\mathrm{I}}\right)$ was measured again. From the plotted dependence between $\left(\mathrm{I}-\mathrm{I}_{\mathrm{I}}\right) / \mathrm{I}$ and $\log _{2}$ of external $\mathrm{K}^{+}$concentration the external potassium concentration $\left(\mathrm{K}_{\mathrm{ex}}^{+}\right)$, for which no change in $\operatorname{DiSC}_{3}(5)$ fluorescence intensity occurs upon valinomycin addition, was calculated. The transmembrane potential $\left(E_{m}\right)$ was calculated from the Nernst equation for monovalent ions (24): 


$$
E_{m}=\frac{R \cdot T}{F} \ln \frac{K_{\text {ex }}^{+}}{K_{\text {in }}^{+}}
$$

where $\mathrm{E}_{\mathrm{m}}$ is the transmembrane potential, $\mathrm{T}, \mathrm{R}$ and $\mathrm{F}$ are temperatures, gas constant and Faraday's constant, respectively. $\mathrm{K}_{\text {ex }}^{+}$is extracellular potassium concentration and $\mathrm{K}^{+}$in is intracellular potassium concentration of erythrocytes $(152 \mathrm{mmol} / \mathrm{L})$.

\section{Statistical analysis}

Statistical analysis of the results was performed using the STATISTICA 12.0 (StatSoft PL) software. Statistical analysis was conducted using the Dunnett test (post-hoc test - ANOVA) at significance level $\alpha=0.01$ or $\alpha=0.05$. All the experiments were done in at least five replicates, the results were presented as mean \pm standard deviation.

\section{RESULTS AND DISCUSSION}

\section{Hemolytic and antioxidant activity of bear garlic extract}

Studies on the hemolytic activity of the extract, tested in a wide range of concentrations (0.01-0.1 $\mathrm{mg} / \mathrm{mL}$ ), showed that the compounds it contains do not induce hemolysis of erythrocytes. The percentage of hemolysis of erythrocytes modified with the extract did not significantly differ from that of control cells (results not included). We also tested the effect of the extract on hemolysis of AAPH- treated erythrocytes. This compound at $37^{\circ} \mathrm{C}$ undergoes hemolytic decomposition, inducing the creation of free radicals (25), which by oxidizing the erythrocyte membrane cause damage and consequent break down of its continuity and leakage of hemoglobin.
In those studies, the percentage of hemolysis was determined for erythrocytes preincubated with extract at concentrations within the range 4-40 $\mu \mathrm{g} / \mathrm{mL}$, and then exposed to the action of AAPH. The percentage of inhibition of AAPH-induced hemolysis was calculated relative to oxidized erythrocytes which had not been treated with the extract. The results showed that bear garlic extract protects erythrocytes from oxidative damage, measured here as the percentage of hemolysis. In the examined concentration range of extract the inhibition of hemolysis was $12.0 \%$ for the lowest concentration of extract (4 $\mu \mathrm{g} / \mathrm{mL}$ ) and ca. $77 \%$ for $40 \mu \mathrm{g} / \mathrm{mL}$ (Fig. 1). The efficacy of bear garlic extract proved to be better than that of $\mathrm{L}(+)$ ascorbic acid. This is evident from comparison of $\mathrm{IC}_{50}$ values for both substances: for the extract $\mathrm{IC}_{50}=20.6 \pm 0.82 \mu \mathrm{g} / \mathrm{mL}$, whereas for ascorbic acid it is $\mathrm{IC}_{50}=32.5 \pm 4.2 \mu \mathrm{g} / \mathrm{mL}$.

Oxidation of erythrocyte membrane lipids by AAPH in presence of bear garlic extract was investigated on isolated red blood cell membranes (ghosts) using the fluorimetric method. The degree of oxidation inhibition caused by the extract was calculated on the basis of the relative intensity of fluorescence, after 30 min oxidation. Fluorescence intensity of the probe decreases with increasing concentration of free radicals in the samples. The results (Fig. 1) show that relative fluorescence intensity increased with increasing concentration of extract, as a result of decreasing concentration of free radicals in the samples; the largest effect occurring at an extract concentration of $8 \mu \mathrm{g} / \mathrm{mL}$. To estimate the antioxidant activity of the extract with respect to membrane lipids, the investigation was also con-
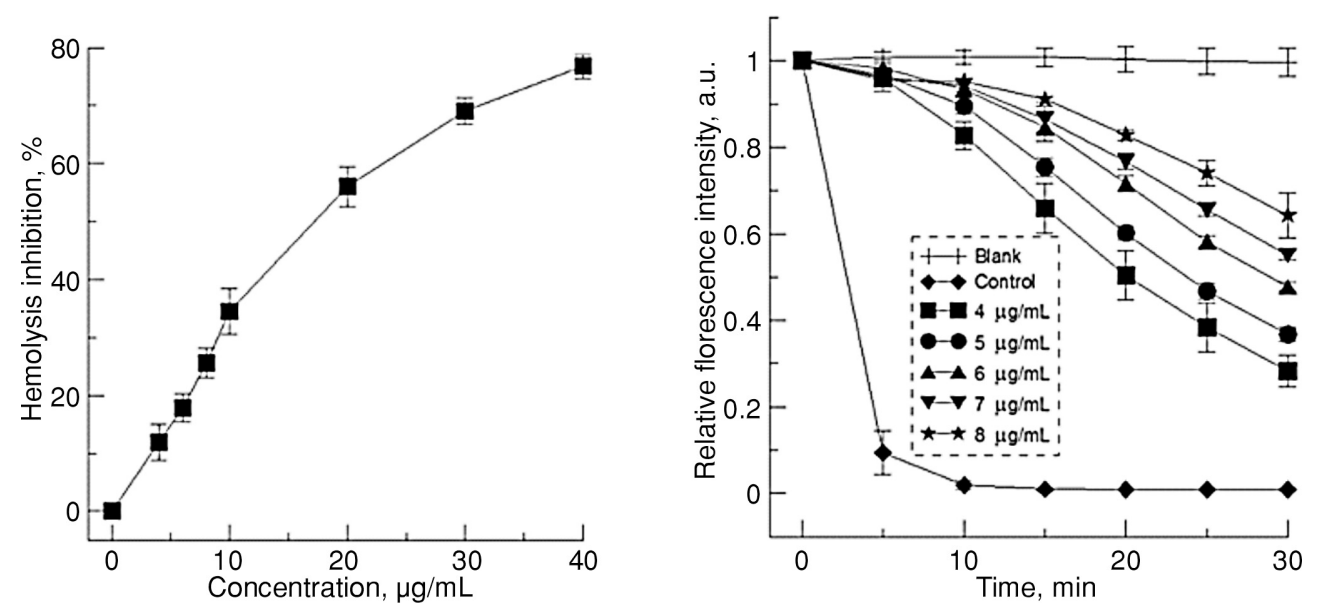

Figure 1. Percentage of oxidative damage (hemolysis) inhibition of erythrocytes, induced by AAPH compound for different concentrations of bear garlic extract (left). Relative fluorescence intensity of TMA-DPH probe for different times of AAPH-induced oxidation of erythrocyte membranes, for control and extract-modified samples (right) 
ducted for the standard antioxidant $(\mathrm{L}+)$ ascorbic acid, resulting in the determination of concentrations responsible for $50 \%$ inhibition of lipid oxidation $\left(\mathrm{IC}_{50}\right)$. The antioxidant activity of the extract is considerably higher than that of ascorbic acid because the same level of oxidation inhibition (50\%) was achieved at a lower extract concentration $\left(\mathrm{IC}_{50}\right.$ $=6.43 \pm 0.19 \mu \mathrm{g} / \mathrm{mL})$ than for ascorbic acid $\left(\mathrm{IC}_{50}=\right.$ $20.5 \pm 1.78 \mu \mathrm{g} / \mathrm{mL}$ ).

The spectrophotometric studies of the extract hemolytic and antioxidant activity showed that extract's constituents do not exert destructive action on erythrocytes, but effectively protect them against free radicals induced by AAPH compound. Furthermore, the fluorimetric studies revealed that extract ingredients not only protect whole erythrocytes but also their membrane against oxidation induced by free radicals. The observed protective effects resulted from chemical reduction of free radicals, which had been bound to the membrane of erythrocytes during their preincubation with the extract. The plant polyphenolic compounds, also kaempferol present in garlic extract, belong to effective scavengers of free radicals, because of the presence of $\mathrm{OH}$ groups in their molecules (25). Lowering the concentration of the free radicals in the solution diminishes the extent of oxidation of erythrocyte membranes and thus protects the lipids and proteins from radical-induced damage that can disturb membrane function, the transport one including, and ultimately leads to hemolysis.

\section{The impact of the extract on physical properties of erythrocytes and their membranes}

In order to determine the location of extract components in the erythrocyte membrane, we performed tests with the fluorescence probes Laurdan and DPH, that embedded in hydrophilic and hydrophobic membrane area, respectively. We studied the effect of bear garlic leaves extract on orientation and packing order of the polar heads of lipids in the erythrocyte membrane and fluidity of its hydrophobic core. Based on fluorescence intensity, we calculated the generalized polarization (GP) of Laurdan probe using formula [2] and fluorescence anisotropy (A) of DPH probe from formula [3]. Extract concentrations used in this investigation were within the range of $10-100 \mu \mathrm{g} / \mathrm{mL}$. A clear decrease in GP with increasing extract concentration was found (Table 1), this signifying increased disorder of the hydrophilic area of the erythrocyte membranes. The approx. 50\% decrease in GP of Laurdan probe for the highest concentration of extract means that the polar heads of membrane lipids underwent modification caused by the presence of extract molecules, which were probably adsorbed to the membrane as a result of electrostatic interaction between the hydrophilic groups of extract polythenols and the polar heads of lipids. The presence of the compounds in the hydrophilic membrane area may increase the number of water molecules surrounding the phosphate and carbonyl groups of lipids, thus a disturbance of the interaction between them may occur, with a consequent change in their orientation and packing (26).

The results obtained with DPH probe, in the form of calculated values of that probe's fluorescence anisotropy, undergo small changes only at highest concentrations of extract, amounting to 50, 75 and $100 \mu \mathrm{g} / \mathrm{mL}$ (Table 1). Smaller values of fluorescence anisotropy signify a small decrease in the fluidity of the hydrophobic area, which is determined both by the packing and mobility of the hydrophobic chains of membrane lipids. One can thus think that the extract polyphenols bind mainly to the erythrocyte membrane but do not penetrate its

Table 1. Values of generalized polarization (GP) of Laudan probe, fluorescence anisotropy (A) of DPH probe and membrane potential $\left(\mathrm{E}_{\mathrm{m}}\right)$ in control and extract modified erythrocytes membrane or erythrocytes.

\begin{tabular}{|c|c|c|c|}
\hline $\begin{array}{c}\text { Concentration } \\
\mu \mathrm{g} / \mathrm{mL}\end{array}$ & $\begin{array}{c}\text { GP } \\
\text { a.u. }\end{array}$ & $\begin{array}{c}\mathbf{A} \\
\text { a.u. }\end{array}$ & $\begin{array}{c}\mathbf{E}_{\mathrm{m}} \\
\mathrm{mV}\end{array}$ \\
\hline 0 & $0.255 \pm 0.025$ & $0.229 \pm 0.003$ & $-11.9 \pm 1.1$ \\
\hline 10 & $0.231 \pm 0.024^{\mathrm{a}}$ & $0.225 \pm 0.004$ & $-11.6 \pm 1.0$ \\
\hline 25 & $0.189 \pm 0.021^{\mathrm{b}}$ & $0.218 \pm 0.004^{\mathrm{a}}$ & $-11.4 \pm 1.2$ \\
\hline 50 & $0.157 \pm 0.012^{\mathrm{b}}$ & $0.207 \pm 0.007^{\mathrm{a}}$ & $-11.3 \pm 1.3$ \\
\hline 75 & $0.137 \pm 0.006^{\mathrm{b}}$ & $0.202 \pm 0.005^{\mathrm{a}}$ & $-10.8 \pm 0.8^{\mathrm{a}}$ \\
\hline 100 & $0.120 \pm 0.011^{\mathrm{b}}$ & $0.202 \pm 0.001^{\mathrm{a}}$ & $-9.9 \pm 0.9^{\mathrm{a}}$ \\
\hline
\end{tabular}

Results are expressed as an average \pm SD of five experiments. Statistically significant results are denoted $\left({ }^{\mathrm{a}} \mathrm{P}<0.1,{ }^{\mathrm{b}} \mathrm{P}<0.05\right)$ 


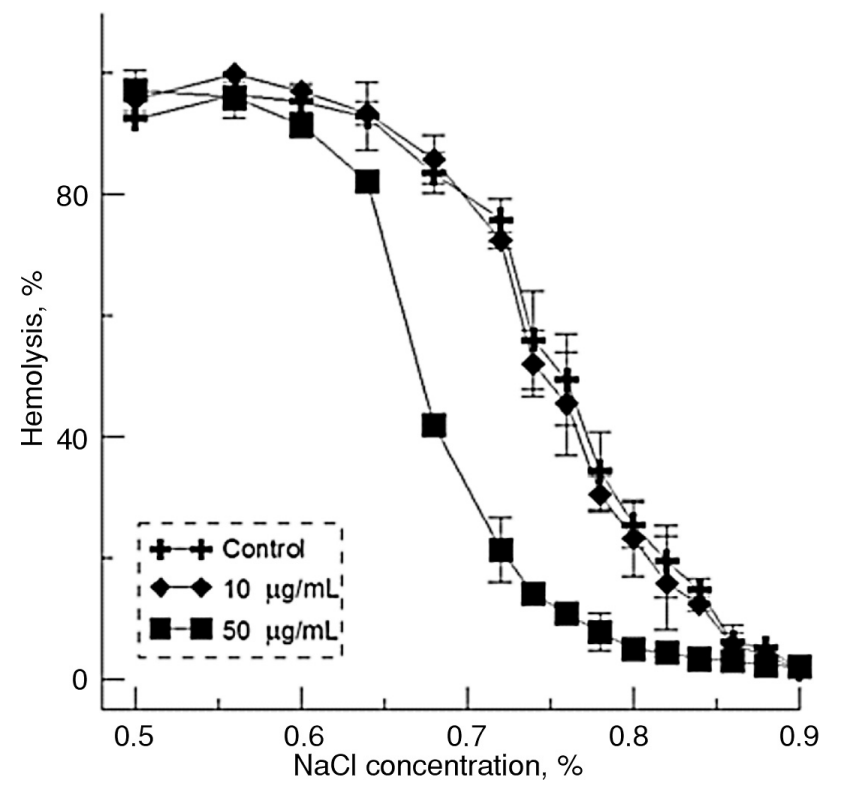

Figure 2. Percentage of hemolysis of control and extract-modified erythrocytes at 0.01 and $0.05 \mathrm{mg} / \mathrm{mL}$ versus sodium chloride concentration

hydrophobic core. These small changes in the fluidity of the hydrophobic region seem to be the consequence of alterations occurring in the hydrophilic region of the membrane. The extract compounds do not penetrate the region of hydrocarbon chains of lipids due to both the size of the sugar groups of quercetin glycosides and their hydrophilic character. Not only polyphenols contained in bear garlic but also other substances present in leaves of that plant possess the ability to make the lipid membrane more fluid $(16,17)$.

We also studied the effect of the extract on osmotic resistance of erythrocytes in hypotonic solutions of sodium chloride. For this, the erythrocytes were incubated in isotonic solutions containing the bear leaf extract of 10 and $50 \mu \mathrm{g} / \mathrm{mL}$ concentration. Extract-modified erythrocytes were suspended in hypotonic solutions of sodium chloride and the percentage of hemolysis was measured relative to $100 \%$ hemolysis caused by distilled water. The results (Fig. 2) show that modification of the erythrocytes with extract of a higher concentration, $50 \mu \mathrm{g} / \mathrm{mL}$, causes smaller hemolysis in hypotonic $\mathrm{NaCl}$ solutions, i.e. an increase in osmotic resistance of erythrocytes. It means that the erythrocyte membrane modified by the extract is less susceptible to changes in osmotic pressure of the medium, compared with susceptibility of unmodified cells (control). Since the osmotic resistance of the erythrocyte depends on the permeability of its membrane and on its surface to volume ratio (27), it can be assumed that substances contained in the extract bind to the hydrophilic membrane area and thus "seal" it against water penetrating into the erythrocyte. This is possible because the compounds can form hydrogen bonds with the polar groups of lipids, expelling water molecules and/or restricting their permeation into the lipid bilayer (28). The extract's kaempferol glycosides possess various sugar groups which are capable to intercalate with the phospholipid headgroups through hydrogen bonding and replace smaller sized water molecules from the membrane surface (29).

The found changes induced by the extract in the physical properties of the erythrocyte membrane indicate that extract components may also induce, directly or indirectly, changes in transmembrane potential of the cell. A typical value of the potential for normal healthy erythrocytes is within the range 10 to $-15 \mathrm{mV}$ (29), which reflects potassium permeability of the erythrocyte membrane and depends on the concentration of the ions within and outside cell. The fluorimetric study with $\mathrm{DiSC}_{3}(5)$ probe showed that the presence of extract in the erythrocyte membrane only slightly modifies the value of its electric potential (Table 1). The calculated membrane potential is $-11.9 \mathrm{mV}$, which does not significantly differ from blood cells modified with extract of 10 to 
$50 \mu \mathrm{g} / \mathrm{mL}$ concentration. With erythrocytes modified with 75 and $100 \mu \mathrm{g} / \mathrm{mL}$, we observed diminished value of transmembrane potential, which was -10.8 and $-9.9 \mathrm{mV}$, respectively. This signifies that compounds contained in extract slightly limit ion permeation across the membrane. That small sealing of membrane is brought about by extract molecules being bound to the hydrophilic area of the membrane. This, in turn, causes a reorganization of that membrane area, involving changing inclination of the polar heads of lipids and resultant relocation of electric charges on the surface of the membrane. Such type of change may also result in alterations of the activity of membrane ionic exchangers.

Results of our study indicate that the polyphenolic compounds, aside of other biologically active components of bear garlic, may participate in the healthy properties of this plant. It is possible because they exhibit substantial capacity to protect the cells and their membranes against oxidation, by effectively scavenging free radicals present in the aqueous medium. This is possible because they become embedded mainly in the hydrophilic region of membrane and/or at its surface, and diminish free radicals concentration by neutralizing them and inhibiting free-radical reactions, thereby protecting both the protein and lipid components of the membrane against oxidation. The polyphenolic extract from bear garlic also modifies the physical properties of the membrane, it slightly lowers its transmembrane potential, making the membrane more fluid and more resistant to changes in medium tonicity. The observed decrease in membrane potential, increase in membrane fluidity and osmotic resistance of erythrocytes in the presence of the substances make us believe that they not only can protect the membrane against oxidation buy also can operate against deleterious changes induced in membranes and cells exposed to oxidative stress. It is well known that oxidative stress causes alterations in physical properties of cell membranes; among others, it makes the erythrocyte membrane more rigid, more susceptible to osmotic pressure and hyperpolarized with significantly higher transmembrane potential $(24,30)$.

\section{CONCLUSION}

Bear garlic extract proves to be a rich source of flavonoids, among them mostly kaempferol glycosides. The results of this biophysical study on erythrocytes and their ghosts have shown that the extract has very good protective properties. In the studied concentration range, the extract does not induce hemolysis of erythrocytes but strengthens them, and makes them more resistant to changes in osmotic pressure of the medium. Flavonoids contained in the extract markedly inhibit hemolysis of erythrocytes oxidized with AAPH compound. Extract from the leaves of bear garlic is a more potent antioxidant than ascorbic acid in relation to lipids contained in the erythrocyte membrane. In addition, the extract compounds interact mainly with the hydrophilic part of membrane, which allows them to slightly affect the membrane fluidity and membrane electrical potential. Based on the results of the study, it is evident that phenolic substances contained in garlic interact with the polar part of the membrane and therefore protect the membrane from oxidation, and will thus diminish the risk of illnesses caused by oxidative stress. In addition, changes induced by extract components in the physical properties of the membranes indicate that garlic constituents can play a vital role in ameliorating the damaging activity of free radicals. Thus, it may be hoped that extracts of that valuable plant will be applied as nutraceuticals in functional food, health protection and treatment of many diseases.

\section{Acknowledgments}

This work was financially supported from funds on statutory activities of the Department of Physics and Biophysics of Wroclaw University of Environmental and Life Sciences.

\section{REFERENCES}

1. Simopoulos A.P., Gopalan C.: Plants in Human Health and Nutrition Policy. World Rev. Nutr. Diet., vol. 91, pp I-XIII, Basel, Karger 2003.

2. Lavecchia T., Rea G., Antonacci A., Giardi M.T.: Crit. Rev. Food Sci. Nutr. 53, 198 (2012).

3. Bayan L., Koulivand P.H., Gorji A.: Avicenna J. Phytomed. 4, 1 (2014).

4. Rana S.V., Pal R., Vaiphei K., Sharma S.K., Ola R.P.: Nutr. Res. Rev. 24, 60 (2011).

5. Gitin L., Dinic R., Neagu C., Dumitrascu L.: J. Food Drug. Anal. 22, 425 (2014).

6. Pavlović D.R., Veljković M., Stojanović N.M., Gočmanac-Ignjatović M., Mihailov-Krstev T. et al.: Pharm. Pharmacol. 69, 1208 (2017).

7. Radulović N.S., Miltojević A.B., Stojković M.B., Blagojević P.D.: Food Res. Internat. 78, 1 (2015).

8. Rajasekaran R., Kuan-Hung L., Lee-Yan S.: J. Trad. Complement. Med. 2, 192 (2011). 
9. Reuter H.D.: Phytomedicine 2, 73 (1995).

10. Lachowicz S., Kolniak-Ostek J., Oszmiański J., Wiśniewski R.: J. Food Process. Preserv. 41, 1 (2017).

11. Carotenuto A., de Feo V., Fattorusso E., Lanzotti V., Magno S., Cicala C.: Phytochemistry 41, 531 (1996).

12. Moresco H.H., Colla G., Cavalcante I.D., Queiroz G.S., Pizzolatti M.G., Brighente M.C.: Nat. Prod. Res. 30, 2624 (2016).

13. Chen A.Y., Chen Y.C.: Food Chem. 138, 2099 (2013).

14. Tomšik N., Pavli B., Vladic J., Ramic M., Brindza J., Vidovic S.: Ultrason. Sonochem. 29, 502 (2016).

15. Štajner D., Popović B.M., Čanadanović-Brunet J., Štajner M.: Fitoterapia 79, 303 (2008).

16. Godevac D., Vujisic L., Mojovic M., Ignjatovic A., Spasojevic I., Vajs V.: Food Chem. 107, 1692 (2008).

17. Ezer N., Sahin I., Kazanci N.: Vib. Spectrosc. 89, 1 (2017).

18. Dodge J.T., Mitchell C., Hanahan D.J.: Arch. Biochem. 100, 119 (1963).

19. Peterson G.L.: Anal. Biochem. 83, 346 (1977).

20. Arora A., Nair M.G., Strasburg G.M.: Free Radical Bol. Med. 24, 1355 (1998).
21. Lakowicz J.R.: Fluorescence polarization, in: Principles of fluorescence spectroscopy. pp. 111-153, Plenum Press, New York 2006.

22. Parasassi T., Krasnowska E.K., Bagatolli L., Gratton E.: J. Fluoresc. 8, 365 (1998).

23. Zavodnik B., Piasecka A., Szoslad K., Bryszewska M.: Scand. J. Clin. Lab. Invest. 57, 59 (1997).

24. Zavodnik B., Lapshina E.A., Rekawiecka K., Zavodnik L.B., Bartosz G., Bryszewska M.: BBA- Biomembranes 1421, 306 (1997).

25. Rice-Evans C.A., Miller N.J., Paganga G.: Free Radic. Med. 20, 933 (1996).

26. Phan H.T.T, Yoda T., Chahala B., Morita M., Takagi M., Vestergaarda M.C.: BBABiomembranes 1838, 2670 (2014).

27. Saxena R.K., Seshadri V.: Indian J. Physiol. Pharmacol. 27, 1 (1983).

28. Roy A., Dutta R., Kundu N., Banik D., Sarkar N.: Langmuir 32, 5124 (2016).

29. Lassen U.V.: Electrical potential and conductance of red cell membrane, in: Membrane transport in red cells. Ellory J.C., Lew V.L., Eds. pp. 137-150, Academic Press 1977.

30. Walski T., Chludzińska L., Komorowska M., Witkiewicz W.: BioMed Res. Int. ID 162102 (2014).

Received: 15.10 .2018 